\title{
Age-related Decline in Kv3.1b Expression in the Mouse Auditory Brainstem Correlates with Functional Deficits in the Medial Olivocochlear Efferent System
}

\author{
Martha L. Zettel, ${ }^{1,5}$ Xiaoxia Zhu, ${ }^{1,5}$ William E. O’Neill, ${ }^{2,3,4}$ and Robert D. Frisina ${ }^{1,2,3,5}$ \\ ${ }^{1}$ Department of Otolaryngology, University of Rochester, Rochester, NY 14642, USA \\ ${ }^{2}$ Department of Neurobiology and Anatomy, School of Medicine and Dentistry, University of Rochester, Rochester, \\ NY 14642, USA \\ ${ }^{3}$ Center for Navigation and Communication Sciences, University of Rochester, Rochester, NY 14642, USA \\ ${ }^{4}$ Department of Brain and Cognitive Sciences, College of Arts, Sciences and Engineering, University of Rochester, Rochester, \\ NY 14642, USA \\ ${ }^{5}$ International Center for Hearing and Speech Research, National Technical Institute for the Deaf, Rochester Institute \\ of Technology, Rochester, NY 14623, USA
}

Received: 6 September 2006; Accepted: 21 January 2007; Online publication: 15 February 2007

\begin{abstract}
Kv3.1b channel protein is widely distributed in the mammalian auditory brainstem, but studies have focused mainly on regions critical for temporal processing, including the medial nucleus of the trapezoid body (MNTB) and anteroventral cochlear nucleus (AVCN). Because temporal processing declines with age, this study was undertaken to determine if the expression of Kv3.1b likewise declines, and if changes are specific to these nuclei. Immunocytochemistry using an anti-Kv3.1b antibody was performed, and the relative optical density of cells and neuropil was determined from $\mathrm{CBA} / \mathrm{CaJ}$ mice of four age groups. Declines in expression in AVCN, MNTB, and lateral superior olive (35, 26, and 23\%) were found, but changes were limited to neuropil. Interestingly, cellular optical density declines were found in superior paraolivary nucleus, ventral nucleus of the trapezoid body, and lateral nucleus of the trapezoid body (24, 29, and 26\%), which comprise the medial
\end{abstract}

Correspondence to: Martha L. Zettel • Otolaryngology Department • University of Rochester Medical Center • 601 Elmwood Avenue, Rochester, NY 14642-8629, USA. Telephone: +1-585-2751924; fax: +1-585-2718552; email: Martha_Zettel@urmc.rochester.edu olivocochlear (MOC) feedback system. All declines occurred by middle age (15 months old). No agerelated changes were found in the remaining regions of cochlear nucleus or in the inferior colliculus. Contralateral suppression of distortion-product otoacoustic emission amplitudes of age-matched littermates also declined by middle age, suggesting a correlation between Kv3.1 expression and MOC function. In search of more direct evidence for such a correlation, Kv3.1b knockout mice were examined. Knockouts show poor MOC function as compared to +/+ and +/- genotypes. Thus, Kv3.1b expression declines in MOC neurons by middle age, and these changes appear to correlate with functional declines in efferent activity in both middleaged CBA mice and Kv3.1b knockout mice.

Keywords: voltage-gated $\mathrm{K}+$ channels, medial olivocochlear system, auditory processing, presbycusis, aging, otoacoustic emissions

\section{INTRODUCTION}

The Kv3.1 potassium channel is a member of the Shaw family of voltage-gated potassium channels known for its high activation threshold $(\sim-10 \mathrm{mV})$ and rapid activation and deactivation kinetics (Kanemasa et al. 
1995). The Kcnc1 gene yields two Kv3.1 subtypes (a and b) through alternate splicing (Luneau et al. 1991), but Kv3.1b has been shown to predominate in the adult rodent brain (Perney et al. 1992; Gan and Kaczmarek 1998). Kv3.1b function and expression have been studied extensively in the rodent auditory brainstem, but research has concentrated on regions like the medial nucleus of the trapezoid body (MNTB) and the bushy cell region of the anteroventral cochlear nucleus (AVCNa) where neurons are capable of firing at very rapid rates. Studies suggest that Kv3.1b channel protein is critical for the rapid repolarization of the action potential required for such activity (Brew and Forsythe 1995; Wang et al. 1998b; Brew and Forsythe 2005). Moreover, mice with hearing impairment exhibit a decline in Kv3.1 expression in the MNTB (von Hehn et al. 2004).

However, the Kv3.1b channel protein is not confined to the aforementioned areas and is, in fact, widely distributed throughout the rodent auditory brainstem (Perney et al. 1992; Weiser et al. 1994; Perney and Kaczmarek 1997; Grigg et al. 2000), indicating its possible involvement in other aspects of auditory processing. For example, the superior olivary complex (SOC) is heavily reactive for anti-Kv3.1b antibody, and expression is not confined solely to regions with neurons capable of high firing rates. Moreover, Kv3.1b is expressed in many of the periolivary nuclei, including those giving rise to the medial olivocochlear efferent system (MOC).

The MOC is thought to be important for enhancing signal processing in background noise, and because aging mice and humans have difficulty with this task (Willott 1991; Frisina and Frisina 1997; Snell and Frisina 2000; Snell et al. 2002), age-related changes in this region are of particular interest. The purpose of this study was threefold. The first aim was to determine whether Kv3.1b levels were altered with age in the mouse auditory brainstem and whether expression changes were unique to regions with neurons capable of high discharge rates. To accomplish this, relative optical density (ROD) of anti-Kv3.1b immunostaining was examined at cellular and regional levels in the cochlear nucleus (CN), SOC, and inferior colliculus (IC) of CBA/CaJ mice from 3 to 34 months old (mo). The second aim was to compare age-related changes in Kv3.1b expression with multiple measures of auditory function to determine whether there was any correlation between channel expression and behavior. Auditory brainstem responses (ABRs) were obtained to assess threshold auditory sensitivity at different ages. Distortion-product otoacoustic emissions (DPOAEs) were used to assess outer hair cell (OHC) function, and contralateral suppression (CS) of DPOAE amplitude was used as a measure of MOC reflex strength. Finally, the extent to which changes in
Kv3.1b expression and measures of auditory function occur independently was evaluated. After identifying similarities in the age-related decline in Kv3.1b expression and MOC function, tests were performed on Kv1.3b null-mutant (knockout) mice to determine the extent to which Kv3.1b channel expression contributes to MOC reflex function.

\section{MATERIALS AND METHODS}

All procedures described below were approved by University of Rochester's animal care and use committee and comply with all federal and state regulations. All mice were raised from birth in a separate facility within the University of Rochester Vivarium with ambient noise levels $<50 \mathrm{~dB}$ sound pressure level (SPL).

\section{Subjects}

Group 1. Cohorts of five CBA/CaJ mice $(n=20$, mix of females and males) from four age groups (3-4, 15, 24-26, and 29-34 mo) were processed for Kv3.1b immunocytochemistry. Auditory brainstem response thresholds were obtained within 1 month of death using the protocol described in a subsequent section.

Group 2 (Kv3.1 knockouts). Hearing sensitivity and MOC function were tested in young (6-11 weeks old) Kcnc1 wild-type $(+/+, n=8)$, heterozygous $(+/-, n=8)$, and homozygous knockout $(-/-; n=5)$ mice by obtaining ABR thresholds, DPOAEs, and CS of DPOAEs. These mice were of a mixed genetic background (129/Sv-C57Bl/6-ICR, 25:25:50) and were kindly provided by Dr. Rolf Joho (Southwestern Medical Center, University of Texas). In addition, a wild-type and a null-mutant mouse from this group were processed for Kv3.1b immunocytochemistry. Alternate sections were double-labeled with antibodies against Kv3.1b and choline acetyltransferase (ChAT).

\section{Immunocytochemistry}

Mice were taken during the daytime portion of the light/dark cycle and deeply anesthetized with 0.05 to $0.1 \mathrm{ml}$ (depending on weight) of a $60-\mathrm{mg} / \mathrm{ml}$ sodium pentobarbital solution, intracardially exsanguinated for $10 \mathrm{~min}$ with phosphate-buffered saline (PBS) containing $0.1 \%$ heparin and $0.5 \%$ sodium nitrate, and perfused for 25 min with buffered $4 \%$ paraformaldehyde ( $\mathrm{pH}$ 7.4). The ears were examined postmortem for blockage or infection and the bodies examined for gross abnormalities such as tumors or organ enlargements; none were found. The brains were removed, postfixed in $4 \%$ paraformaldehyde overnight, and 
cryoprotected using successive solutions of 10 and 30\% sucrose in PBS. Thirty-micrometer-thick sections were cut on a cryostat at $-18^{\circ} \mathrm{C}$ and stored in cryoprotectant at $0^{\circ} \mathrm{C}$ until just before the immunocytochemical reactions. To minimize experimental variability, brains were perfused, cryoprotected, and cut within the shortest possible time, and all brain sections in each subject group were immunoreacted together in divided dishes. Every fourth section of each brain was reacted with a 1:200 dilution of anti-Kv3.1b channel protein isolated from rabbit (Alomone Labs, Jerusalem, Israel). An anti-rabbit peroxidase kit (Vector, Burlingame, CA, USA) was used to complete the reaction, and the reaction product was intensified with nickel sulfate yielding a dark purple end-product. In addition, one $K c n c 1$ wild type $(+/+)$ and one $K c n c 1$ knockout $(-/-)$ were taken after the DPOAE portion of this study and treated in an identical manner to determine the specificity of the Kv3.1b antibody used. The Kcnc1 $1+/+$ sections showed an identical staining pattern to the CBA mouse, whereas the knockout sections exhibited no staining, thereby verifying the specificity of the Kv3.1 antibody. Alternate sections obtained from these mice were further reacted using a 1:250 dilution of anti-ChAT antibody (Chemicon, Temecula, CA, USA). An anti-goat peroxidase kit (Vector) was used to complete the reaction, yielding a brown end-product.

\section{Imaging and density determinations}

Photomicrographs were captured at 24 bits per pixel resolution (8 bpp x 3 colors) using a Spot Insight Color digital camera (Diagnostic Instruments, Sterling Heights, MI, USA) attached to a Nikon (Tokyo, Japan) Eclipse E400 microscope. Care was taken to ensure that each image was captured using identical exposure parameters and all images of a particular region were captured on the same day to minimize illumination variability. Images were saved as TIFF files. Because all brains were processed together, no normalization was required within each group. ROD was determined from the digital images automatically using Image Pro Plus 4 (Media Cybernetics, Silver Springs, MD, USA) by measuring the amount of light transmitted per pixel and applying the optical density formula:

$$
\begin{aligned}
\mathrm{OD}=- & \log _{10}[(\text { sample intensity }- \text { black }) \\
& /(\text { incident }- \text { black })]
\end{aligned}
$$

The incident level (intensity $=255$ ) for this experiment was calibrated by acquiring an image of a cover-slipped slide with no tissue. The black level (intensity $=0$ ) was calibrated by acquiring an image with the light source blocked. Sample intensity values were normalized to yield ROD values from 0 (incident) to 1 (black).

Relative optical density was determined in various regions of the $\mathrm{CN}, \mathrm{SOC}$, and IC by capturing all available images for each region as previously described. Each region of interest was manually outlined in Image Pro, and the mean ROD for each region was determined. This measurement is referred to as the regional $R O D$, and is a measure of both cellular and neuropil Kv3.1b immunostaining. In this study, only nuclei that showed an age-related statistically significant change in regional ROD were analyzed further. In these areas, each reactive cell was manually outlined to calculate its ROD and somatic area. Mean density (Kv3.1b+ cells $\left./ \mathrm{mm}^{2}\right)$ was also determined. If an area showed a decline in regional ROD (cells + neuropil) but the cellular ROD remained the same across age, it was assumed that the changes were neuropil-related. To detect subtle changes, it was critical to optimize the light levels for each nucleus examined. Thus, cross-nuclear comparisons of ROD were not possible. Statistical analyses were performed with GraphPad Prism ${ }^{\circledR} 4.03$ (GraphPad Software, San Diego, CA, USA) and SPSS $^{\circledR}$ v.13 (SPSS, Chicago, IL, USA).

It should be noted that the anti-Kv3.1b antibody used in this study does not distinguish between phosphorylated and nonphosphorylated states of the channel protein. Moreover, the thickness of the sections $(30 \mu \mathrm{m})$ and the technique used in this study made it impossible to resolve age-related changes in Kv3.1b distribution at the level of the cell membrane.

\section{Auditory brainstem response audiometry}

Auditory brainstem response audiograms were obtained with a TDT System 3 auditory evoked potential workstation running BioSigRP(C) software (TuckerDavis Technologies, Alachua, FL, USA) on a Dell personal computer. Mice were lightly anesthetized with ketamine/xylazine (120 and $10 \mathrm{mg} / \mathrm{kg}$ ) and placed on a 10-cm-high platform inside a small (length, width, and height $=57 \times 41 \times 36 \mathrm{~cm}$ ), electrically shielded soundproofed booth (IAC) lined with 4.5-cm-thick echo-attenuating acoustic foam (Sonex ${ }^{\circledR}$; Illbruck Acoustic, Minneapolis, MN, USA). The mouse was arranged in a prone position facing a broad-band electrostatic loudspeaker system (TDT ES1 and ED1 speaker driver) located $10 \mathrm{~cm}$ from the head, and was kept warm during the procedure with a circulatingwater heating pad. Miniature subdermal needle electrodes (Nicolet Biomedical, Madison, WI, USA) were inserted at the vertex (reference), over the bulla (active), and just above the hind limb (ground). Auditory brainstem response waveforms were recorded (total gain $5,020 \times, 3-1,000 \mathrm{~Hz}$ ) with a TDT RA4LI low- 


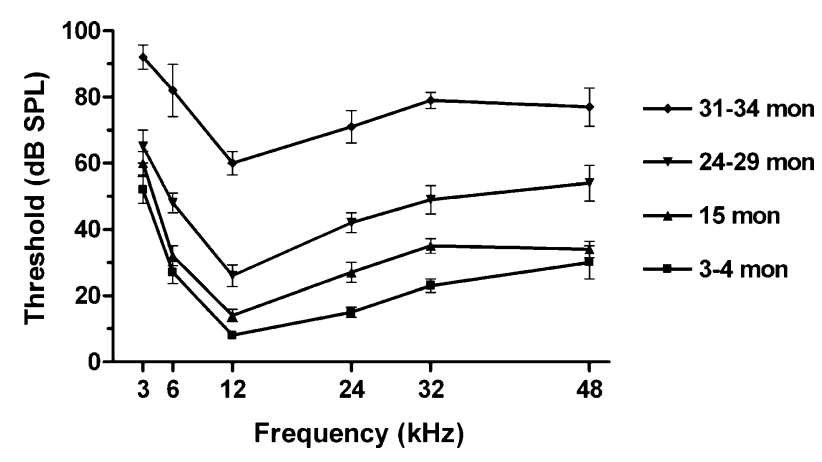

FIG. 1. $A B R$ audiograms for CBA mice used in the Kv3.1b immunocytochemistry portion of this study. Each curve represents mean $A B R$ wave $V$ thresholds obtained with 5-ms pure-tone stimuli (1 $\mathrm{ms}$ rise/fall time) presented at the indicated stimulus frequencies. A gradual "flat" increase in threshold is seen across frequencies with increasing age, but overall, the thresholds remain relatively low until very old age.

impedance digital headstage and RA4PA Medusa preamp controlled by a RA16 digital signal processor. Calibrated tone bursts ( $5 \mathrm{~ms}$ in duration, $0.5 \mathrm{~ms}$ risefall time, phase alternating $90^{\circ}$ ) were synthesized with SigGenRPC software on a TDT RP2.1 real-time processor and presented at a rate of 10/s at frequencies of 3, 6, 12, 16, 24, 32, and $48 \mathrm{kHz}$. Auditory brainstem response waveforms were averaged in response to 300 tone bursts $(150 \times 2$ blocks $)$ at each tested frequency/amplitude combination. At each frequency, the amplitude of the signal was automatically attenuated (TDT PA5) in 5-dB steps between samples from $90 \mathrm{~dB}$ SPL $(\mathrm{dB}$ re $20 \mu \mathrm{Pa})$ until the wave IV - V complex of the ABR waveforms was no longer distinguishable by eye from background. By convention, threshold was established as the response at $5 \mathrm{~dB}$ above this final level.

\section{Distortion-product otoacoustic emissions in Kv3.1b knockout mice}

Distortion-product otoacoustic emissions were obtained on the mice in group $2(K c n c 1+/+,+/-$, and $-/-)$ following ABR audiometry as described previously (Jacobson et al. 2003; Guimaraes et al. 2004). Briefly, under anesthesia (ketamine/xylazine, 120 and $10 \mathrm{mg} / \mathrm{kg}$, respectively) a combination microphone/speaker system was placed in the test ear, and an identical speaker was inserted into the contralateral ear. Acoustic stimuli were delivered and DPOAE waveforms were recorded using BioSig-RPC software and TDT System III hardware (Tucker-Davis Technologies). The digitally synthesized stimulus $(200 \mathrm{kHz}$ sample rate) consisted of two primary pure-tone frequencies $\left(f_{1}\right.$ and $\left.f_{2}\right)$ differing by a factor of 1.25 , at 65 and $55 \mathrm{~dB}$ SPL, respectively. A fast Fourier transform was performed on the resultant waveform recorded from the insert microphone, and the spectral magnitude of the two primaries, the $2 f_{1}-f_{2}$ distortion product, and the noise floor were determined. The procedure was repeated for $f_{1}$ frequencies ranging from 5.6 to $44.8 \mathrm{kHz}$.

Mice were tested using two different conditions alternated three to four times in a random order. In the first condition, the stimulus was administered monotically under quiet conditions to obtain the DPOAE. In the second, a 55-dB SPL wideband noise was simultaneously applied to the contralateral ear to measure contralateral suppression of the DPOAE (CSDPOAE). The 55-dB level was chosen so as to be below the middle ear muscle reflex in mice, a variety of other mammals, and humans (Puel and Rebillard 1990; Williams and Brown 1995; Liberman et al. 1996; Sun and Kim 1999; Buki et al. 2000; Kujawa and Liberman 2001). The noise floors under both conditions were statistically evaluated for each of the three genotypes independently across all frequencies to assure a lack of interaural crosstalk.

The magnitude of the CS-DPOAE was calculated for each $f_{1}$ frequency as the amplitude of the DP in contralateral noise minus the amplitude in quiet. One-way ANOVA was performed on the CS-DPOAEs across the three genotypes, and if the main effect (genotype) was statistically significant $(p<0.05)$, a Bonferroni-corrected multiple-comparison post hoc test was performed. In addition, a two-way ANOVA for genotype mean CSDPOAE by stimulus frequency was calculated.

\section{RESULTS}

Auditory brainstem response threshold audiograms in CBA mice

Auditory brainstem response thresholds were evaluated for the group 1 (CBA) mice in each age group prior to their being killed for immunocytochemistry. A two-way ANOVA showed a significant effect of frequency $(p<0.0001)$ and age $(p<0.0001)$ but no significant interaction between the two factors $(p=0.57)$. The results (Fig. 1) indicated that "middle-aged" (15 mo) CBA mice had thresholds statistically equal to "young" (3-4 mo) mice at all frequencies. In contrast, "old" $(24-29 \mathrm{mo})$ mice had significantly $(p<0.01)$ elevated thresholds $(20-30 \mathrm{~dB})$ at all tested frequencies except $3 \mathrm{kHz}$. "Very old" mice $(31-34 \mathrm{mo})$ suffered from severe hearing loss (>60 dB; $p<0.001)$ across all frequencies. This pattern of progressive, "flat" hearing loss (i.e., loss across the entire hearing range) is characteristic of aged CBA mice (Willott 1991).

\section{Kv3.1b expression with age}

For clarity, brainstem regions examined in this study were divided into three groups based upon the pattern of anti-Kv3.1b immunostaining. 

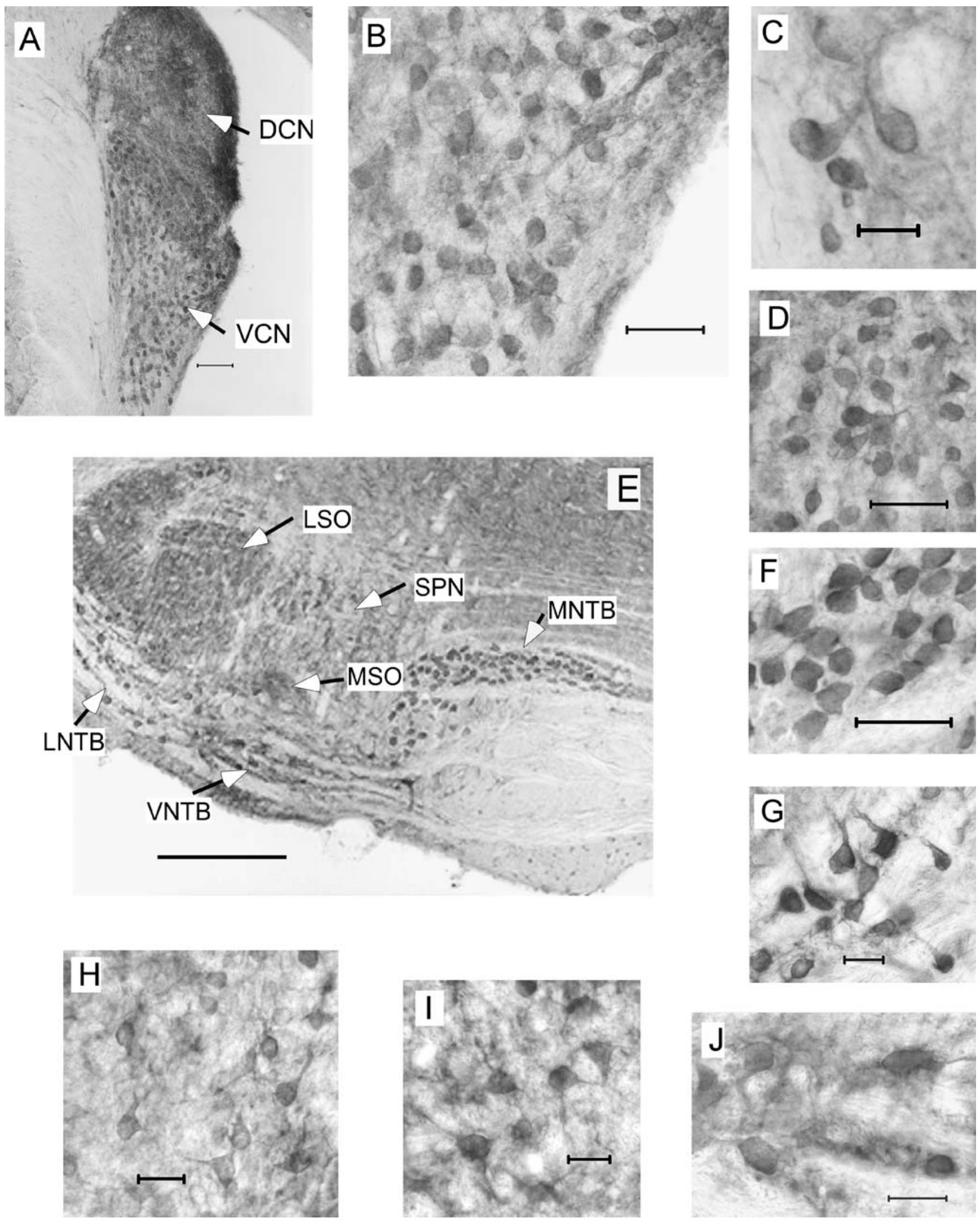
Regional ROD

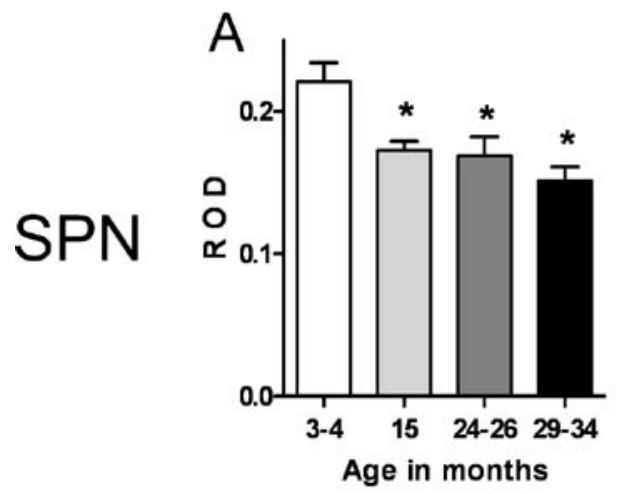

Cell Area
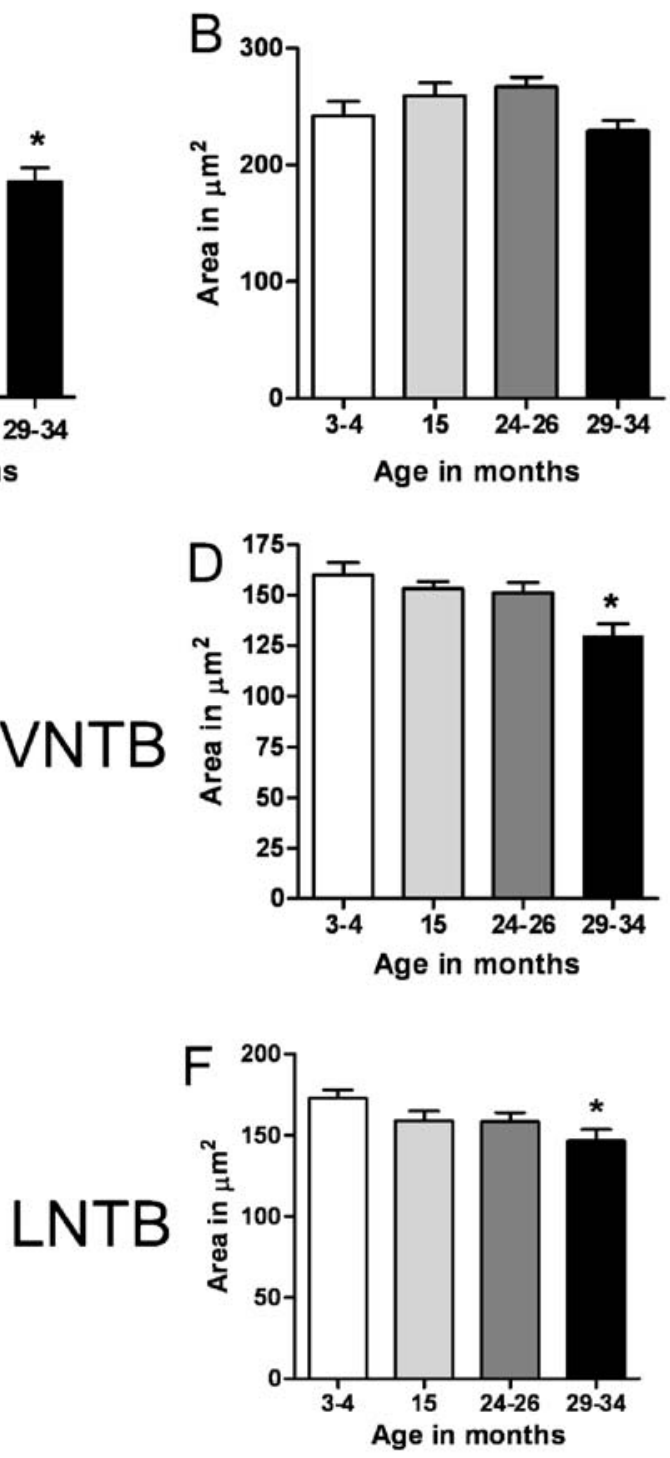

Cell ROD

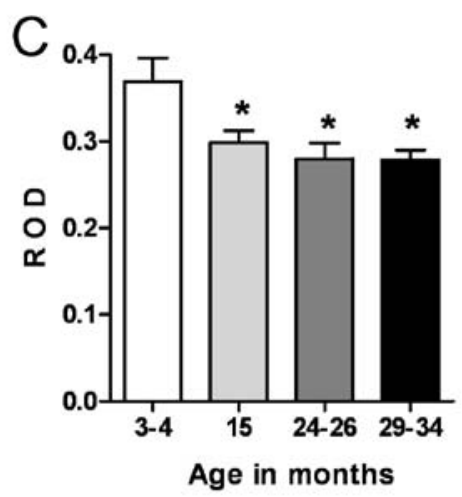

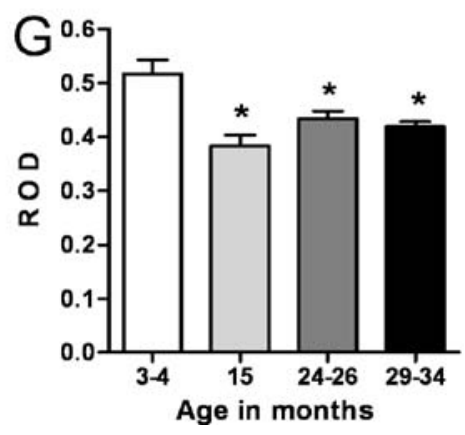

FIG. 3. Kv3.1b expression as a function of age. A SPN regional ROD. Significant decline occurs by 15 months. B SPN cell area. No decline with age is seen. C SPN cellular ROD. Significant decline occurs by 15 months. D VNTB cell area. Decline occurs only in oldest mice. E VNTB cellular ROD. A significant decline occurs by 15 months. F LNTB cell area. A gradual decline with age is seen and only reaches significance in the oldest mice. G LNTB cellular ROD. Significant decline occurs by 15 months. Error bars are standard errors of the mean. Asterisks indicate significant difference $(p<0.05)$ from $3-4$ mo. ROD = relative optical density.

FIG. 2. Photomicrographs of Kv3.1b+ cells and neuropil in the CBA mouse. A Cross-section of brainstem at the level of the DCN and VCN. DCN has heavily stained neuropil but no immunoreactive cells. VCN has numerous Kv+ cells and immunopositive neuropil. $S c a l e ~ b a r=75 \mu m$. B Immunopositive neurons in the VCN. Scale bar $=50 \mu \mathrm{m}$. C Very lightly immunoreactive octopus cells of the VCN. Scale bar=25 $\mu \mathrm{m}$. D Heavily reactive globular bushy cells and neuropil of the AVCNa. Scale bar $=50 \mu \mathrm{m}$. E Cross-section of the brainstem at the level of the SOC. The LSO is large and easy to distinguish by its intensely immunoreactive neuropil but lack of any immunopositive cells. In contrast, the MSO is small and indistinct. Scale bar $=200 \mu \mathrm{m}$. F Strongly Kv+ principal cells and neuropil of the MNTB. Scale bar $=50 \mu \mathrm{m}$. G Darkly stained cells of the LNTB intercalated between highly myelinated nonreactive fibers of the ventral acoustic stria. Scale bar $=25 \mu \mathrm{m}$. H Kv+ cells of the ICc. Scale bar $=25 \mu \mathrm{m}$. I Large immunoreactive cells of the SPN. Neuropil is only lightly stained. Scale bar $=25 \mu \mathrm{m}$. J Kv+ VNTB cells intercalated between fibers of the acoustic stria. Scale bar $=25 \mu \mathrm{m}$. 
Regional ROD

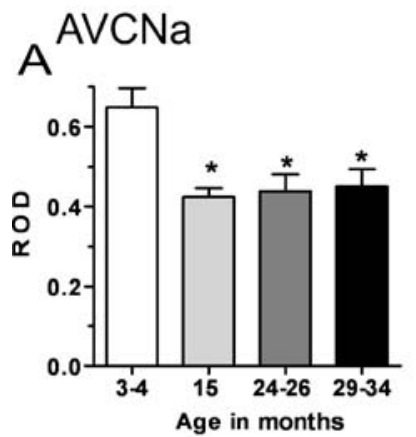

\section{MNTB}

E

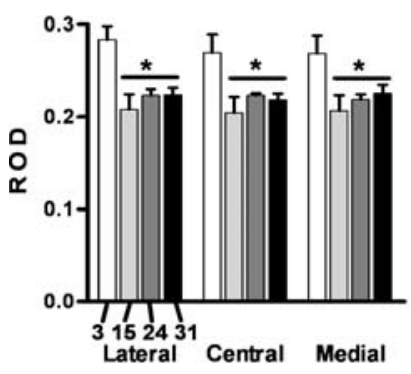

F

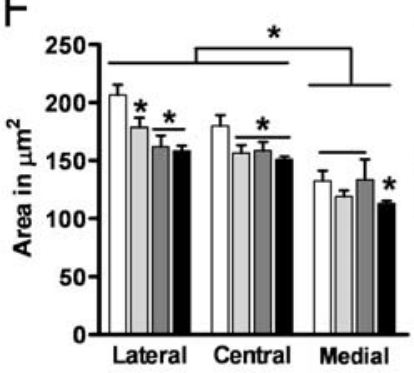

Cell ROD
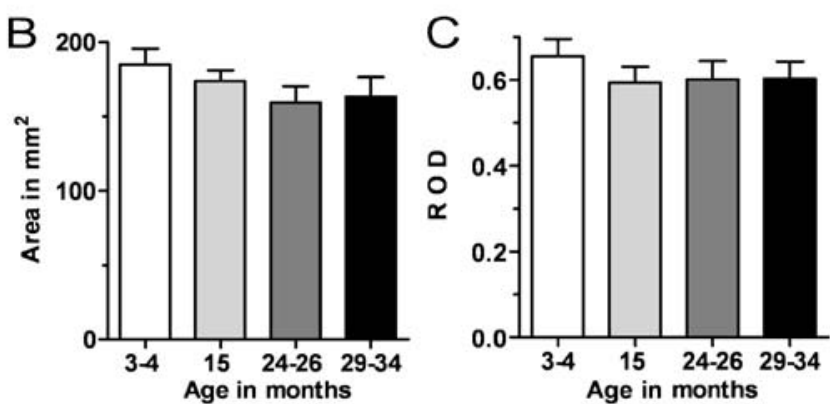

G

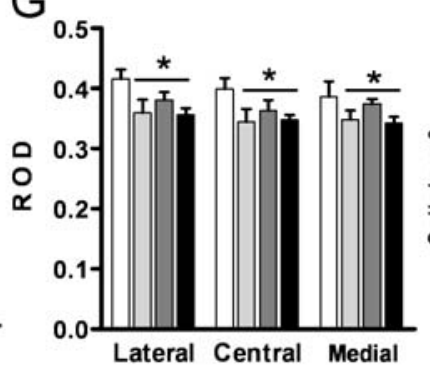

Cell Density

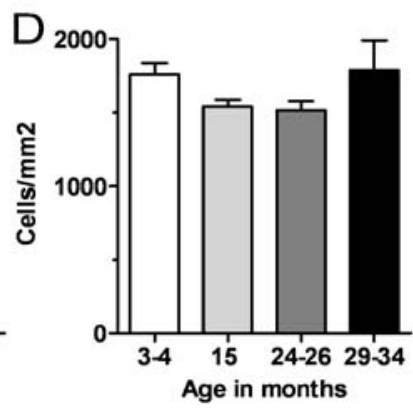

$\mathrm{H}$

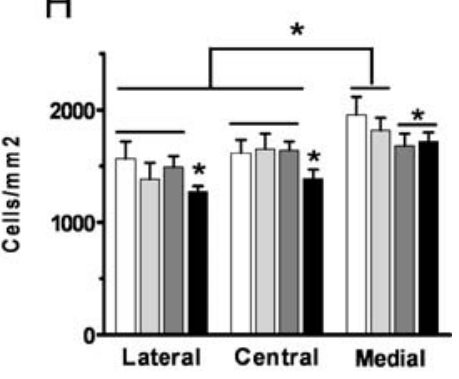

I

\section{LSO}

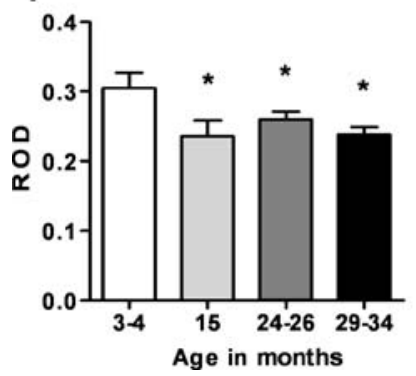

FIG. 4. Brainstem regions that show decline in regional, but not cellular, expression of Kv3.1b with age. A AVCNa regional ROD. Significant decline occurs by 15 months. B AVCNa cellular ROD. No decline with age is seen. C AVCNa cell area. No decline is seen. D AVCNa cell density $\left(\right.$ cells $\left.\mathrm{s} / \mathrm{mm}^{2}\right)$. No decline in cell density with age is found. $\mathbf{E}-\mathbf{H}$ Kv3.1b immunoreactivity in the lateral, central, and medial MNTB. E MNTB regional ROD. Significant decline is found by $15 \mathrm{mo}$ in all regions (shading indicates age groups, as in A). F MNTB cell area. Cell size declines with age, but the decline occurs at different rates in the three regions. Laterally and centrally, significant decline occurs by 15 mo. Medially, cell size remains the same until $31 \mathrm{mo}$. Kv+ cell size also declines along the lateral-to-medial tonotopic gradient, with the lateral and central regions significantly different from the medial region. G MNTB cellular ROD declines with age significantly between 3 and 15 mo in all regions. H MNTB cell density (cells $/ \mathrm{mm}^{2}$ ). A gradual age-related decline in density was found in the medial region that was significant between 3 and $15 \mathrm{mo}$, whereas the there was no decline in density until $31 \mathrm{mo}$ in the lateral and central regions. There was also a significant gradient of increasing density from lateral to medial. I LSO regional ROD. A significant decline is seen by 15 months. No cellular staining was present. Error bars are standard errors of the mean. Horizontal lines above bars in $\mathbf{E}-\mathbf{H}$ indicate age groups or regions in MNTB with no significant differences; asterisks indicate significant differences $(p<0.05)$. ROD = relative optical density.

\section{Regions showing age-related declines in cellular} Kv3.1b expression

Superior paraolivary nucleus. In the mouse, the superior paraolivary nucleus (SPN) is located dorsal to the very small medial superior olive (MSO), and medial to the much larger lateral superior olive (LSO; Fig. 2E). Both cell bodies and neuropil were $\mathrm{Kv}+$. One-way ANOVA showed that the mean regional ROD in the SPN declined significantly with age $(p=0.0048 ; F=6.37$; total $d f=19)$, and post hoc tests revealed that the significant decline $(22 \% ; p<0.05)$ occurred between 3 and $15 \mathrm{mo}$, and thereafter remained stable into very old age (Fig. 3A). Kv+ cells in young mice had large spherical cell bodies (Fig. 2I) with mean areas of $242 \mu \mathrm{m}^{2}$, and showed no significant area change with age (Fig. 3B). Notably, mean cellular ROD (Fig. 3C) did decline with age $(24 \% ; p=0.011 ; F=5.28$; total $d f=18$ ), with the greatest significant decline in expression (19\%) occurring between the 3 and 15 mo mice. 

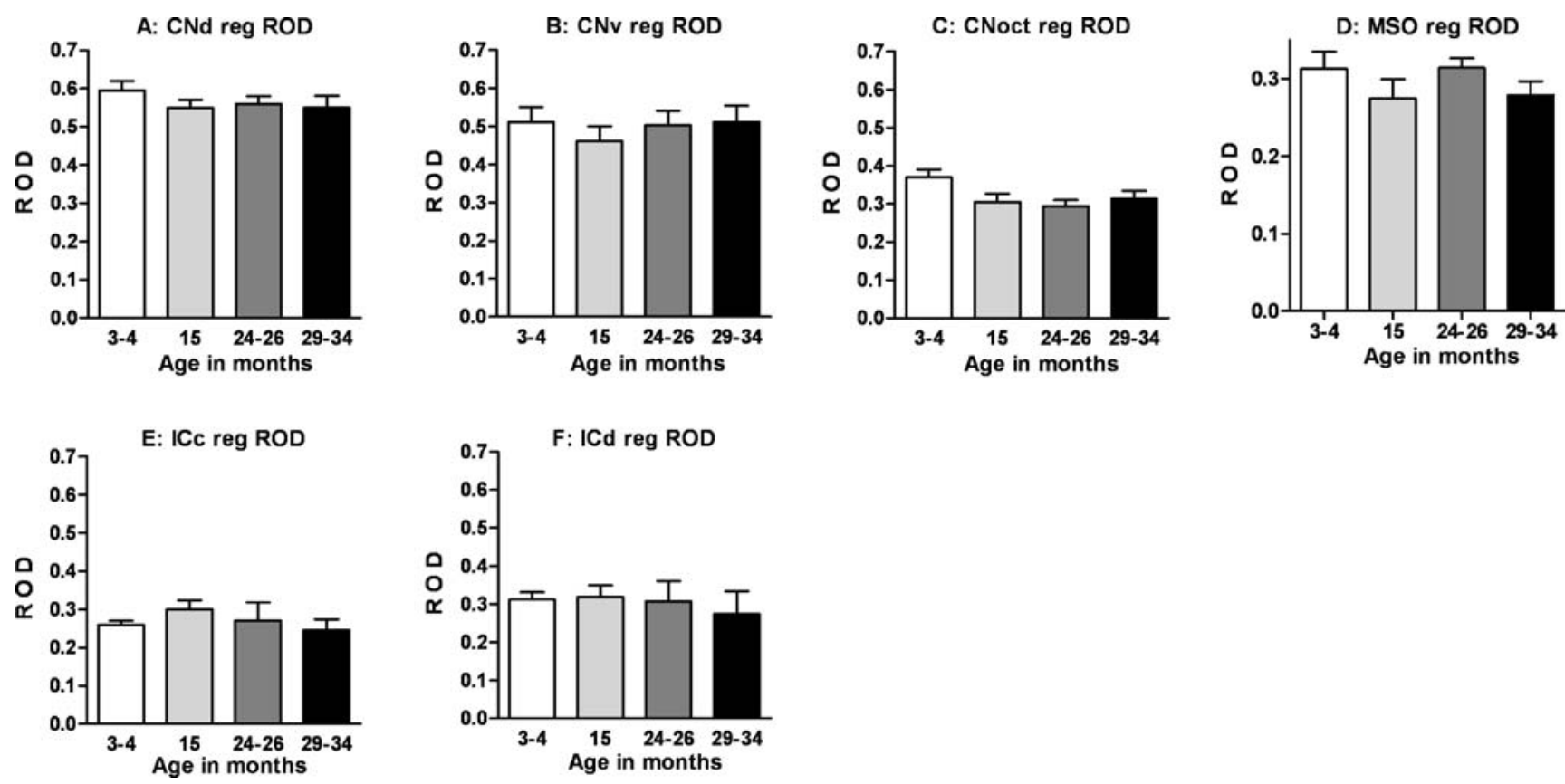

FIG. 5. Auditory brainstem regions that show no statistically significant declines in Kv3.1b expression with age. A Dorsal cochlear nucleus. B Ventral cochlear nucleus outside of AVCNa. C Octopus cell region of VCN. D Medial superior olive. E Central nucleus of the IC. F Dorsal division of the IC. Error bars are standard errors of the mean. ROD = relative optical density.

Ventral nucleus of the trapezoid body. The ventral nucleus of the trapezoid body (VNTB) is a periolivary nucleus ventral to the MSO and SPN whose cells are tightly embedded among the highly myelinated fibers of the ventral acoustic stria (trapezoid body) traversing the inferior surface of the brainstem (Fig. 2E). Due to the presence of the trapezoid body fibers, the VNTB has no clear boundary or visible neuropil, and thus, no regional ROD values were obtained. VNTB $\mathrm{Kv}+$ cells (Fig. 2J) had a mean somatic area of $160 \mu \mathrm{m}^{2}$ in young mice and showed a small but significant decline in size $(4 \% ; p=0.007 ; F=5.94$; total $d f=18)$ only in very old mice (Fig. 3D). Cellular ROD declined 29\% ( $p=0.006$; $F=6.34$; total $d f=17$ ) with age, with the statistically significant decline occurring between 3 and 15 mo (27\%; $p<0.01$; Fig. 3E).

Lateral nucleus of the trapezoid body. The lateral nucleus of the trapezoid body (LNTB) is a periolivary nucleus ventral and lateral to the LSO that, like the VNTB, is embedded in the ventral acoustic stria (Fig. 2E). As with the VNTB, no regional ROD values were obtained. LNTB cells (Fig. 2G) had a mean area of $173 \mu \mathrm{m}^{2}$ in young mice, and showed a significant age-related decline in size $(15 \% ; p=0.047 ; F=3.34$; total $d f=18)$ that reached significance $(p<0.01)$ only in the oldest mice (Fig. 3F). Cellular ROD declined 26\% ( $p=0.002$; $F=8.22$; total $d f=18$ ) between 3 and $15 \mathrm{mo}$, after which it remained stable into old age (Fig. 3G).
Regions showing age-related declines in neuropil, but not somatic, Kv3.1b expression

Anterior division of AVCN. The AVCNa was distinguished from other regions of the $\mathrm{CN}$ by its numerous, highly reactive, spherical and globular bushy cells (Fig. 2D). Both cell bodies and neuropil were $\mathrm{Kv}+$ in AVCNa. The regional ROD showed the largest age-related decline in expression of any region of interest in this study $(35 \% ; p=0.008$; $F=5.89$; total $d f=17$ ), and this decline occurred between 3 and 15 mo (Fig. 4A). By contrast, cellular ROD showed no change with age (Fig. 4B), and therefore, the decline in regional ROD was attributable to expression changes in the neuropil. To assure that the decline in regional ROD was not caused by a decline in the size or number of $\mathrm{Kv}+$ cells, changes in cell area and density $\left(\right.$ cells $\left./ \mathrm{mm}^{2}\right)$ with age were determined. Overall, neither cell area $\left(\right.$ mean $=185 \mu^{2}$ ) nor density (mean $=1,762$ cells $/ \mathrm{mm}^{2}$ ) changed significantly with age in AVCNa (Fig. 4C, D).

Medial nucleus of the trapezoid body. The MNTB is the most medially located nucleus of the SOC (Fig. 2E) and was easily identified by the highly reactive $\mathrm{Kv}+$ neuropil and numerous darkly stained principal cells (Fig. 2F). Because it has been reported that Kv3.1b expression varies tonotopically in the mouse MNTB (von Hehn et al. 2004), we divided the MNTB into three equal 

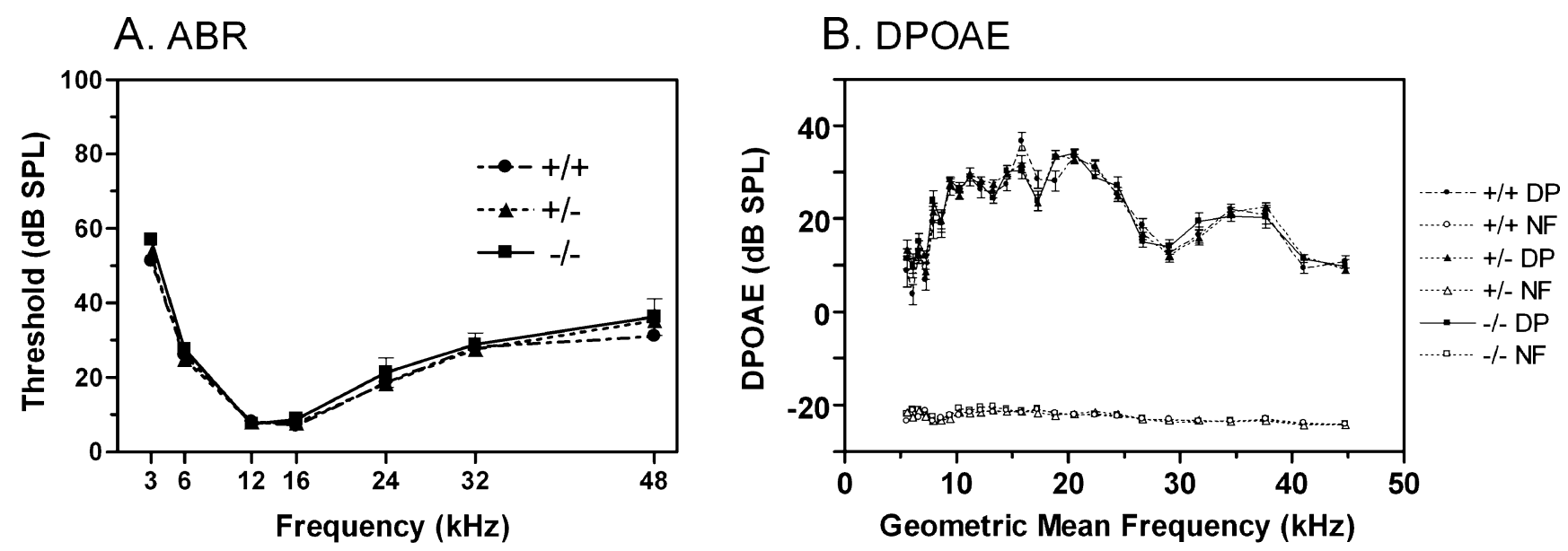

\section{CS-DPOAE}

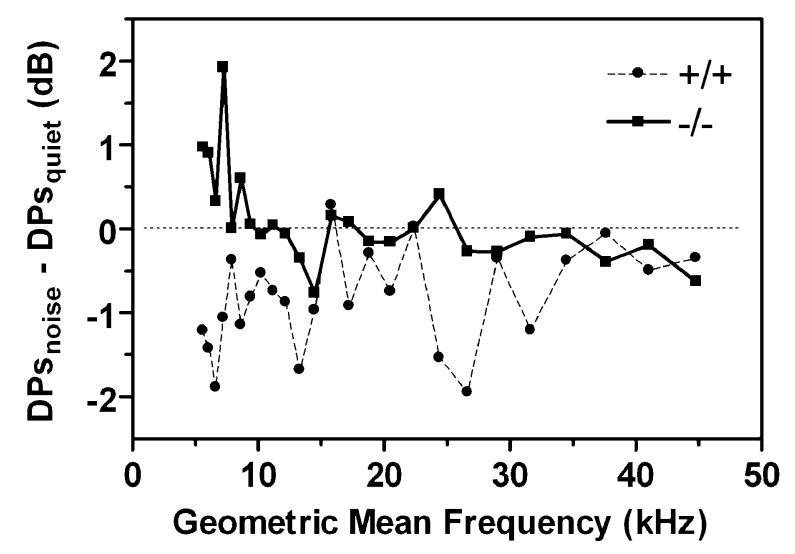

D. CS-DPOAE

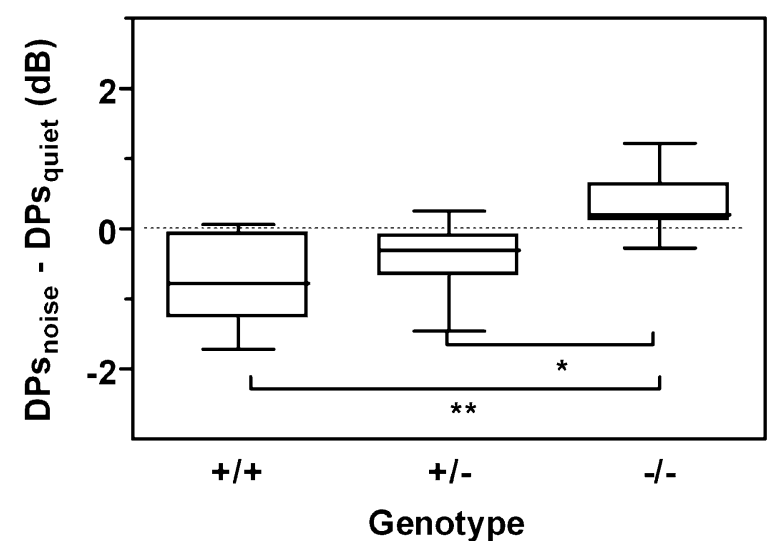

FIG. 6. Comparison of auditory function in Kv3.1b $-/-$ (knockouts), $+/+$, and $+/-$ mice at 6 to 11 weeks of age. A ABR threshold audiograms show no differences among genotypes. B DPOAE amplitudes are well above the noise floor $\left(N F\right.$, bottom traces) for each group at all $f_{1}$ frequencies tested. No differences in amplitude were found among the three genotypes. C Comparison of CS-DPOAE between $-/-$ and $+/+$ genotypes. The knockout mice have no measurable CS and are significantly different from wild-type mice at many frequencies above, and at all frequencies below, $16 \mathrm{kHz}$. D Box plots (median, interquartile ranges, and total range) summarizing CS-DPOAEs of the three genotypes. There was a statistically significant difference between the knockout mice compared to both $+/-$ and $+/+$ mice.

analysis areas roughly corresponding to the low(lateral), mid- (central), and high-frequency (medial) regions of the nucleus to examine Kv3.1b expression in each subdivision separately as a function of age.

A two-way ANOVA showed a highly significant overall effect of age on Kv3.1 regional ROD $(p<0.0001$; $F=16.08 ; d f=3$; Fig. $4 \mathrm{E})$. There was no significant regional difference in ROD expression $(p=0.79$; $F=0.23 ; d f=2)$, nor was there any age/region interaction $(p=0.99 ; F=0.12 ; d f=6)$. Scheffe post hoc analysis showed that the age-related decline in regional ROD occurred between the 3-4 mo and 15 mo mice, and that the magnitude of the decline was the same in all three regions of the MNTB. At $15 \mathrm{mo}$, the lateral (low-frequency) region of MNTB showed a $27 \%$ decline in regional ROD $(p<0.001)$, the central (midfrequency) region showed a $24 \%$ decline $(p<0.01)$, and the medial (high-frequency) region showed a $23 \%$ decline $(p<0.01)$, relative to that at 3 mo. After 15 mo, the regional ROD of all three regions remained statistically unchanged into very old age.

While we did not confirm a tonotopic expression pattern for Kv3.1b regional ROD, we did find a significant mediolateral gradient in the size of $\mathrm{Kv}+$ principal cells (Fig. 4F; two-way ANOVA, $p=0.0004 ; F=36.92$; $d f=2)$. At $3 \mathrm{mo}$, the largest cells were found in the lateral MNTB (mean area $=206.5 \pm 20.57(\mathrm{SD}) \mu \mathrm{m}^{2}$ ), followed by the central region $\left(180.9 \pm 19.41 \mu \mathrm{m}^{2}\right)$ and medial region $\left(132.3 \pm 19.69 \mu \mathrm{m}^{2}\right)$. Post hoc tests revealed significant differences between the medial and lateral region $(p<0.001)$ and between the medial and central region $(p<0.001)$, but not between the lateral and central region $(p=0.19)$. In the lateral region, the $\mathrm{Kv}+$ cell area declined significantly with age between 3 and $15 \mathrm{mo}(p=0.05)$. At $15 \mathrm{mo}$ (Fig. $4 \mathrm{~F}$ ), the decline is $13 \%(p<0.05)$; at $24 \mathrm{mo}$, it is $21 \%$ $(p<0.01)$; and at $31 \mathrm{mo}$, it is $23 \%(p<0.01)$. In the central region, cell area declined more slowly with 


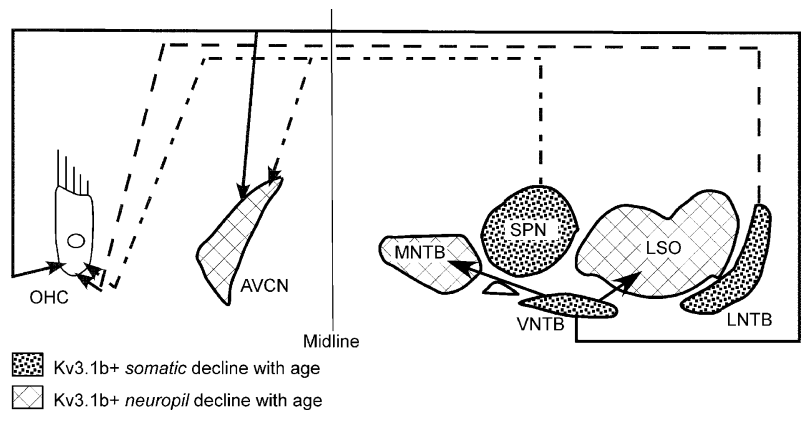

FIG. 7. Illustration showing connections between the MOC nuclei where age-related declines in somatic Kv3.1b expression (stippled) were found and nuclei where Kv3.1+ neuropil declined (hatched). The figure does not show all connections but is meant to demonstrate how decline in neuropil expression in the LSO, MNTB, and AVCNa may at least partially result from declines in expression within MOC neurons projecting to them.

age. The decline was significant between 3 and 15 mo $(p=0.05)$, but thereafter remained the same and statistically indistinguishable from the lateral region. By contrast, $\mathrm{Kv}+$ cell area in the medial region showed no significant age-related decline until 31 mo $(p=0.05)$.

Cellular ROD (Fig. 4G) was not significantly different across the three regions $(p=0.345 ; F=1.09$; $d f=2)$ but did show a decline with age $(p=0.001$; $F=6.49 ; d f=3)$. Similar to the pattern seen for regional ROD (Fig. 4E), the significant decline with age occurred between 3 and $15 \mathrm{mo}$, after which the cell ROD remained the same.

Mean density (Fig. 4H) in the lateral and central regions showed no significant change with age until 31 mo $(p<0.05)$. Cell density in the medial region showed significant age-related declines between 3 and 15 mo. However, there was a gradient in cell density, with the medial region being significantly higher than the lateral region $(p=0.0001)$ and central region $(p=0.006)$, and this gradient was particularly strong in the 31 -mo mice $(p=0.05)$.

In summary, these data indicate that the drop in regional ROD with age (Fig. $4 \mathrm{E}$ ) in the MNTB was caused primarily by a decline in Kv3.1b expression in the neuropil, and not in the cells. Gradients for cell size and density are complementary, with size increasing, and density decreasing, along the mediolateral (i.e., tonotopic) axis.

Lateral superior olive. The LSO had heavily $\mathrm{Kv}+$ neuropil, but no $\mathrm{Kv}+$ cells (Fig. 2E). The regional ROD therefore was an indication of neuropil staining alone, and it declined significantly by 15 mo $(23 \% ; p=0.038$; $F=3.59$; total $d f=18$ ), after which it remained statistically the same into old age (Fig. 4I).

\section{Regions with no age-related changes in Kv3.1b expression}

Cochlear nucleus. The dorsal CN (DCN; Fig. 2A) was distinguished from other regions of the $\mathrm{CN}$ by the presence of very darkly stained neuropil, but a lack of $\mathrm{Kv}+$ cells, similar to LSO (Fig. 2A). Leaving aside the aforementioned AVCNa and the octopus cell region of the posteroventral CN (CNoct), the remainder of ventral $\mathrm{CN}$ (VCN) possessed many darkly stained cells and moderately stained neuropil (Fig. 2A, B). By contrast, the CNoct was only very lightly stained, and it was difficult to tell whether the staining was localized to the octopus cells themselves or to $\mathrm{Kv}+$ endings on their somata (Fig. 2C). There were no age-related declines in the regional ROD of the DCN (Fig. 5A), VCN (Fig. 5B), or CNoct (Fig. 5C).

Medial superior olive. The MSO in mice is extremely small and not easily distinguishable. The neuropil in the vicinity was darkly immunoreactive, but there were no $\mathrm{Kv}+$ cells (Fig. 2E). There was no decline in regional ROD in the MSO with age (Fig. 5D).

Inferior colliculus. The dorsal division of IC (ICd) was distinguished from the central nucleus (ICc) by darkly stained neuropil and a lack of $\mathrm{Kv}+$ cells. ICc in contrast had numerous lightly stained cells and moderately stained neuropil (Fig. 2H). There were no age-related declines in regional ROD in the ICc (Fig. 5E) or ICd (Fig. 5F).

\section{Functional assessment of Kv3.1b} null-mutant mice

The immunocytochemical results show a clear agerelated decline in Kv3.1b expression in brainstem regions giving rise to the MOC. To evaluate the functional consequences of such declines, we obtained ABR audiograms (to assess overall peripheral/brainstem auditory sensitivity), DPOAEs (to measure the strength of the OHC-dependent "cochlear amplifier"), and CS-DPOAEs (to assess the strength of the MOC reflex) in young $K c n c 1+/+,+/-$, and -/mice.

We found no significant differences in ABR thresholds among the three genotypes across frequency (Fig. 6A). Thus, the absence of the Kv3.1b channel protein did not alter overall cochlear or brainstem threshold sensitivity in young mice. DPOAE amplitudes (Fig. 6B) were well above the mean noise floor (curves labeled "NF"). There was no significant difference in DPOAE amplitude among the three genotypes, indicating that the absence of Kv3.1b channel protein did not alter $\mathrm{OHC}$ function. 
Mean CS at each test frequency for Kv3.1b +/+ and $+/-$ genotypes is shown in Figure 6C. Because CS is calculated by subtracting the DP in quiet from that in contralateral noise, larger CS magnitudes are represented by more negative values. Wild-type $(+/+)$ mice showed significant CS of DPOAE, whereas knockouts $(-/-)$ did not, and a two-way ANOVA showed a statistically significant difference in CS in the $-/-$ mice in the low- to mid-frequency region of the audiogram (5$15 \mathrm{kHz}$ ). Statistical analysis of mean CS among the three genotypes (Fig. 6D) showed significantly less suppression in $-/-$ mice as compared to both $+/-$ $(p<0.01)$ and $+/+(p<0.001)$ genotypes, indicating a possible decline in MOC function in Kv3.1b knockout mice.

\section{ChAT/Kv3.1b double-labeling in the MOC}

Because ChAT is known to be expressed in cells comprising the rodent MOC system (Vetter et al. 1991), sections from one wild-type mouse were doublelabeled with ChAT and Kv3.1b antibodies. In the VNTB and LNTB, all cells positive for Kv3.1b were also immunoreactive for ChAT. In the VNTB, the ChAT staining was dark in all Kv3.1b+ cells, whereas in the LNTB, the ChAT intensity varied from light to dark. The SPN was difficult to visualize with this technique because of the heavy neuropil immunoreactivity. It is evident that many of the Kv3.1b-positive cells are also ChAT-positive, but it is not possible to determine if they all are. A future study using fluorescently labeled antibodies will clarify this greatly.

\section{DISCUSSION}

Age-related decline in Kv3.1b expression in the mouse MOC

Examination of the auditory brainstem revealed a number of age-related changes in expression of $\mathrm{Kv} 3.1 \mathrm{~b}$ channel protein. Most intriguing were somatic declines in Kv3.1b expression in SPN, VNTB, and LNTB. These nuclei are unique in that they contain populations of neurons giving rise to the MOC efferent system, which provides negative feedback to OHCs of the cochlea (Liberman and Brown 1986; Campbell and Henson 1988; Maison et al. 2003). In the mouse, MOC arises specifically from SPN and the ventral periolivary nuclei (LNTB and VNTB) (Brown 1993). In our study, SPN, VNTB, and LNTB neurons were strongly Kv3.1b+ and showed significant declines in expression between young (3-4 mo) and middle age $(15 \mathrm{mo})$, after which expression remained stable into very old age. In contrast, there was no change in somatic labeling in LSO, IC, or the remaining regions of $\mathrm{CN}$, indicating that the decline in the MOC-related nuclei was not part of a global decline in somatic in Kv3.1b expression.

However, these results by themselves do not resolve whether $\mathrm{Kv}+$ neurons in SPN, VNTB, and LNTB are actually MOC efferents. In particular, the mouse SPN is large, and it projects to areas other than the cochlea, including MNTB (Helfert et al. 1989) and IC (Frisina et al. 1998). Similarly, VNTB projects to ipsilateral and contralateral VCN, LSO, and LNTB (Schwartz 1992), and LNTB projects to CN (Schwartz 1992), MSO, and LSO (Kuwabara and Zook 1992). Work by others (Vetter et al. 1991) has shown that rodent MOC neurons are immunoreactive for ChAT. In our study, the $\mathrm{Kv}+$ cells of the VNTB, LNTB, and SPN also colabeled with antibodies to ChAT, indicating that they are most likely MOC neurons.

\section{Decline in MOC function with age in $\mathrm{CBA} / \mathrm{CaJ}$ mice}

Previous published studies by our group examined the ABR thresholds, DPOAE, and CS-DPOAE magnitudes across age in colony mates of the CBA mice used in the present report (Jacobson et al. 2003; Varghese et al. 2005). CBA/CaJ mice of three age groups (2 to $4 \mathrm{mo}, n=21 ; 14$ to $16 \mathrm{mo}, n=13$; 24 to $31 \mathrm{mo}, n=22$ ) were examined. ABR thresholds for these mice remained low into old age, comparable to the cohort of CBA mice used in the current study. DPOAE amplitudes were high in young and middleaged CBA mice, indicating a healthy OHC system, and only showed significant declines in the oldest age group. The integrity of the OHC system in middleaged CBA mice is further supported by the lack of any loss in inner or OHCs in the region of the basilar membrane representing $1-70 \mathrm{kHz}$ up to $18 \mathrm{mo}$ (Spongr et al. 1997).

In contrast, the CS-DPOAE values showed a different pattern of age-related deficit. By $15 \mathrm{mo}$, the strength of CS began to decline, and there was almost no CS by 24 mo. Therefore, there is a significant decline in the strength of MOC reflex suppression by middle age, a pattern similar to that in humans (Kim et al. 2002). The decline in CS precedes any significant change in ABR thresholds and DPOAE magnitudes, but correlates nicely with declines in Kv3.1b expression in the MOC of middle-aged mice.

\section{Lack of CS of DPOAEs in Kv3.1 knockout mice}

Although it is tempting to conclude that decline in Kv3.1b expression and MOC function are related, it is also possible that both declines occur independently, or that some other factor drives both declines in parallel. The availability of the Kv3.1 knockout mouse provided a direct way to examine whether the lack of 
Kv3.1 channel protein results in MOC functional decline. Young Kcnc1 null-mutant mice were compared to homo- and heterozygous mice of the same age using ABR thresholds, DPOAE amplitudes, and CSDPOAEs. Both ABR thresholds and DPOAE amplitudes were similar among the three groups (Fig. 6A, B), implying that Kv3.1b is not critical for overall cochlear sensitivity or for OHC function. In contrast, CS was almost completely absent in knockout mice, especially for low frequencies (Fig. 6C). It should be noted that the magnitude of CS in wild-type mice is small, less than $2 \mathrm{~dB}$ in the low-frequency range and less than $1 \mathrm{~dB}$ on average across the spectrum. Therefore, while suppression is nearly eliminated in knockout mice, it remains unclear whether this loss is functionally significant.

Although the functional role this channel plays is not fully understood, Kv3.1 channels have been associated with auditory pathways that have high firing rates and temporal synchrony (Critz et al. 1993; Grissmer et al. 1994; Kanemasa et al. 1995; Wang et al. 1998b; Rudy and McBain 2001). Neurophysiological studies to date suggest that MOC neurons do not have high firing rates, and temporal synchrony in the MOC has not been investigated. Consequently, it is possible that Kv3.1 channels in MOC neurons have neurophysiological properties not solely related to temporal synchrony or high firing rates.

Decline in Kv3.1b expression in the neuropil of rapidly firing auditory nuclei

As mentioned, many studies have shown the importance of Kv3.1b channels in neurons that fire rapidly and with temporal precision, and it is known that the lack Kv3.1b can diminish firing fidelity significantly (Macica et al. 2003). Thus, it was not surprising to find strong expression of Kv3.1b in MNTB, AVCNa, and LSO, where cells with high firing rates and a significant amount of phase-locking are found (Frisina et al. 1985; Joris 1996; Joris and Yin 1998; Frisina 2001; Macica et al. 2003). Also, because declines in temporal processing and sound localization in mice and humans occur with age (Frisina and Frisina 1997; Frisina et al. 1997; Giraud et al. 1997; Frisina and Walton 2001; Frisina 2001; Seidman et al. 2002), significant age-related decline in Kv3.1b expression in these regions was not unexpected. Because peripheral function (ABR and DPOAE) showed noticeable changes only in the oldest mice, whereas Kv3.1 expression declined to its lowest levels in the brainstem by middle age, it is clear that central changes in Kv3.1b may precede the peripheral functional impairment.

Of particular interest was the observation that Kv3.1 decline was not somatic, but instead was con- fined to neuropil in these nuclei. Recent research (Weiser et al. 1995; Sekirnjak et al. 1997; Wang et al. 1998a; Devaux et al. 2003; Dodson and Forsythe 2004) has localized Kv3.1b channel proteins within the somatic membrane, in the axon at the nodes of Ranvier, and in spine-like axonal structures proximal to synaptic endings (Wang et al. 1998a). In our study, we could not observe enough detail to determine whether the decline in neuropil expression occurred in proximal axon segments of AVCNa bushy cells and MNTB principal cells, or in distal segments and/or presynaptic spines of axons from neurons projecting into these nuclei from elsewhere. If the decline is occurring in the proximal axon nodes, then it is intriguing that similar declines were not also seen in the soma. It is certainly plausible that in cells capable of firing at rapid rates, the regulation of Kv3.1b channel protein might be confined to the axon at sites of action potential initiation, but not in the cell body.

However, changes in AVCNa neuropil staining may also be a reflection of declines in Kv3.1b in terminal axonal segments from auditory nerve fibers (Adamson et al. 2002), contralateral CN, DCN, or MOC efferents (Cant 1992). Because the CN shows no age-related decline in somatic expression, the evidence suggests that the decline in AVCNa neuropil labeling may at least be partially attributed to the collateral projections to AVCNa from SPN and/or VNTB MOC efferents, which show a significant decline in Kv3.1b expression by middle-age. Likewise, the decline found in Kv3.1b neuropil expression in MNTB may be caused by a decline in AVCNa bushy cell axons terminating in MNTB. However, this would also require a change in axonal expression in the absence of somatic changes because bushy cells did not show age-related changes in Kv3.1b expression in their cell bodies. It is possible instead that VNTB projections are responsible for the decline in MNTB neuropil labeling because VNTB did show declines in somatic staining with age.

Finally, because LSO has no Kv3.1b-positive cells, the decline in neuropil here would also result from age-related changes in projections from other nuclei. The main projections to LSO originate in AVCN, MNTB, and VNTB (Schwartz 1992), and consequently, projections from VNTB may be the more likely source of Kv3.1b expression changes in LSO. Clearly, further experiments are needed to resolve these uncertainties.

\section{CONCLUSIONS}

Kv3.1b channel protein declined in neuronal cell bodies of the MOC efferent system (SPN, VNTB, and LNTB) in the CBA mouse by middle age ( $15 \mathrm{mo})$, as 
summarized in Figure 7. Previous work by our group has shown decline in MOC function in CBA mice occurring by middle age, and Kv3.1b knockout mice showed poor MOC function as compared to $+/+$ and $+/-$ genotypes. In addition, expression also declined at about the same rate in the neuropil of AVCNa, MNTB, and LSO. This decline is likely traced to distal axon segments and terminals of neurons projecting to these nuclei, and the most likely sources of these projections are the MOC neurons that likewise showed declines in somatic expression. Our data suggest that Kv3.1b channel protein may be important for normal MOC efferent function, and that declines in expression with age may result in functional deficits that precede OHC loss and some of the eventual cochlear pathologies that characterize age-related hearing loss-presbycusis-in mammals, including humans.

\section{ACKNOWLEDGMENTS}

We thank Drs. James Ison and Kathy Barsz (University of Rochester) for statistical assistance, Dr. Rolf Joho (University of Texas Southwestern Medical Center) for providing the founding colony of Kv3.1b knockout mice, and John Housel for collecting the ABR data. This research was funded by United States Public Health Service/NIH grant P01-AGO9524 from the National Institute for Aging, P30DC05409 from the National Institute on Deafness and Communication Disorders, and the International Center for Hearing and Speech Research, Rochester, NY, USA.

\section{REFERENCES}

Adamson CL, Reid MA, Mo ZL, Bowne-English J, Davis RL. Firing features and potassium channel content of murine spiral ganglion neurons vary with cochlear location. J. Comp. Neurol. 447:331 - 350, 2002.

BREw HM, Forsythe ID. Two voltage-dependent K+ conductances with complementary functions in postsynaptic integration at a central auditory synapse. J. Neurosci. 15:8011-8022, 1995.

BREW HM, ForsYTHE ID. Systematic variation of potassium current amplitudes across the tonotopic axis of the rat medial nucleus of the trapezoid body. Hear. Res. 206:116-132, 2005.

BRown MC. Fiber pathways and branching patterns of biocytinlabeled olivocochlear neurons in the mouse brainstem. J. Comp. Neurol. 337:600-613, 1993.

Buki B, Wit HP, Avan P. Olivocochlear efferent vs. middle-ear contributions to the alteration of otoacoustic emissions by contralateral noise. Brain Res. 852:140 - 150, 2000.

Campbell JP, Henson MM. Olivocochlear neurons in the brainstem of the mouse. Hear. Res. 35:271-274, 1988.

CANT N. Neuronal types in the cochlear nucleus. In: Webster DPA and Fay R (eds) Mammalian Auditory Pathway: Neuroanatomy. New York, Springer-Verlag, pp. 66-116, 1992.

Critz SD, Wible BA, Lopez HS, Brown AM. Stable expression and regulation of a rat brain $\mathrm{K}+$ channel. J. Neurochem. 60:11751178, 1993.
Devaux J, Alcaraz G, Grinspan J, Bennett V, Joho R, Crest M, Scherer SS. Kv3.1b is a novel component of CNS nodes. J. Neurosci. 23:4509-4518, 2003.

Dodson PD, Forsythe ID. Presynaptic K+ channels: electrifying regulators of synaptic terminal excitability. Trends Neurosci. $27: 210-217,2004$

FRISINA RD. Subcortical neural coding mechanisms for auditory temporal processing. Hear. Res. 158:1-27, 2001.

Frisina DR, Frisina RD. Speech recognition in noise and presbycusis: relations to possible neural mechanisms. Hear. Res. 106:95-104, 1997.

Frisina R, WaLton J. Aging of the mouse central auditory system. In: Willott J (ed) Handbook of Mouse Auditory Research: From Behavior to Molecular Biology. New York, CRC Press, pp. 339 379, 2001.

Frisina RD, Smith RL, Chamberlain SC. Differential encoding of rapid changes in sound amplitude by second-order auditory neurons. Exp. Brain Res. 60:417-422, 1985.

Frisina RD, Walton JP, Lynch-Armour MA, Klotz DA. Efferent projections of a physiologically characterized region of the inferior colliculus of the young adult CBA mouse. J. Acoust. Soc. Am. 101:2741-2753, 1997.

Frisina RD, Walton JP, Lynch-Armour MA, Byrd JD. Inputs to a physiologically characterized region of the inferior colliculus of the young adult CBA mouse. Hear. Res. 115:61 -81, 1998.

GAN L, KACZMAREK LK. When, where, and how much? Expression of the Kv3.1 potassium channel in high-frequency firing neurons. J. Neurobiol. 37:69-79, 1998.

Giraud AL, Garnier S, Micheyl C, Lina G, Chays A, Chery-Croze S. Auditory efferents involved in speech-in-noise intelligibility. Neuroreport 8:1779-1783, 1997.

Grigg JJ, Brew HM, Tempel BL. Differential expression of voltagegated potassium channel genes in auditory nuclei of the mouse brainstem. Hear. Res. 140:77-90, 2000.

Grissmer S, Nguyen AN, Aiyar J, Hanson DC, Mather RJ, Gutman GA, Karmilowicz MJ, Auperin DD, Chandy KG. Pharmacological characterization of five cloned voltage-gated $\mathrm{K}+$ channels, types $\mathrm{Kv} 1.1,1.2,1.3,1.5$, and 3.1 , stably expressed in mammalian cell lines. Mol. Pharmacol. 45:1227-1234, 1994.

Guimaraes P, Zhu X, Cannon T, Kim S, Frisina RD. Sex differences in distortion product otoacoustic emissions as a function of age in CBA mice. Hear. Res. 192:83-89, 2004.

Helfert RH, Bonneau JM, Wenthold RJ, Altschuler RA. GABA and glycine immunoreactivity in the guinea pig superior olivary complex. Brain Res. 501:269-286, 1989.

Jacobson M, Kim S, Romney J, Zhu X, Frisina RD. Contralateral suppression of distortion-product otoacoustic emissions declines with age: a comparison of findings in CBA mice with human listeners. Laryngoscope 113:1707-1713, 2003.

JoRIs PX. Envelope coding in the lateral superior olive. II. Characteristic delays and comparison with responses in the medial superior olive. J. Neurophysiol. 76:2137-2156, 1996.

Joris PX, YIN TC. Envelope coding in the lateral superior olive. III. Comparison with afferent pathways. J. Neurophysiol. 79:253269, 1998.

Kanemasa T, Gan L, Perney TM, Wang Ly, Kaczmarek LK. Electrophysiological and pharmacological characterization of a mammalian Shaw channel expressed in NIH 3T3 fibroblasts. J. Neurophysiol. 74:207-217, 1995.

Kim S, Frisina DR, Frisina RD. Effects of age on contralateral suppression of distortion product otoacoustic emissions in human listeners with normal hearing. Audiol. Neurootol. $7: 348-357,2002$.

Kujawa SG, Liberman MC. Effects of olivocochlear feedback on distortion product otoacoustic emissions in guinea pig. J. Assoc. Res. Otolaryngol. 2:268-278, 2001. 
Kunabara N, Zook JM. Projections to the medial superior olive from the medial and lateral nuclei of the trapezoid body in rodents and bats. J. Comp. Neurol. 324:522-538, 1992.

Liberman MC, Brown MC. Physiology and anatomy of single olivocochlear neurons in the cat. Hear. Res. 24:17-36, 1986.

Liberman MC, Puria S, Guinan JJ, Jr. The ipsilaterally evoked olivocochlear reflex causes rapid adaptation of the 2f1-f2 distortion product otoacoustic emission. J. Acoust. Soc. Am. 99:3572 - 3584, 1996.

Luneau CJ, Williams JB, Marshall J, Levitan Es, Oliva C, Smith JS, Antanavage J, Folander K, Stein RB, Swanson R, et al. Alternative splicing contributes to $\mathrm{K}+$ channel diversity in the mammalian central nervous system. Proc. Natl. Acad. Sci. USA. 88:3932-3936, 1991.

Macica CM, von Hehn CA, Wang LY, Ho CS, Yokoyama S, Joho RH, KACZMAREK LK. Modulation of the kv3.1b potassium channel isoform adjusts the fidelity of the firing pattern of auditory neurons. J. Neurosci. 23:1133-1141, 2003.

Maison SF, Adams JC, Liberman MC. Olivocochlear innervation in the mouse: immunocytochemical maps, crossed versus uncrossed contributions, and transmitter colocalization. J. Comp. Neurol. 455:406 - 416, 2003.

Perney TM, Kaczmarek LK. Localization of a high threshold potassium channel in the rat cochlear nucleus. J. Comp. Neurol. 386:178-202, 1997.

Perney tM, Marshall J, Martin Ka, Hockfield S, Kaczmarek LK. Expression of the mRNAs for the Kv3.1 potassium channel gene in the adult and developing rat brain. J. Neurophysiol. 68:756-766, 1992.

Puel JL, Rebillard G. Effect of contralateral sound stimulation on the distortion product 2F1-F2: evidence that the medial efferent system is involved. J. Acoust. Soc. Am. 87:1630-1635, 1990.

Rudy B, McBain CJ. Kv3 channels: voltage-gated $\mathrm{K}^{+}$channels designed for high-frequency repetitive firing. Trends Neurosci. 24:517-526, 2001.

SCHWARTZ I. The superior olivary complex and lateral lemniscal nuclei. In: Webster DPA and Fay R (eds) Mammalian Auditory Pathway: Neuroanatomy. New York, Springer-Verlag, pp. 117-167, 1992.

Seidman MD, Ahmad N, Bai U. Molecular mechanisms of age-related hearing loss. Ageing Res. Rev. 1:331-343, 2002.

Sekirnjak C, Martone Me, Weiser M, Deerinck T, Bueno E, Rudy B, Eluisman M. Subcellular localization of the K+ channel subunit Kv3.1b in selected rat CNS neurons. Brain Res. 766:173-187, 1997.
SNell KB, Frisina DR. Relationships among age-related differences in gap detection and word recognition. J. Acoust. Soc. Am. 107:1615-1626, 2000.

Snell KB, Mapes FM, Hickman ED, Frisina DR. Word recognition in competing babble and the effects of age, temporal processing, and absolute sensitivity. J. Acoust. Soc. Am. 112:720 - 727, 2002.

Spongr VP, Flood DG, Frisina RD, Salvi RJ. Quantitative measures of hair cell loss in CBA and C57B1/6 mice throughout their life spans. J. Acoust. Soc. Am. 101:3546-3553, 1997.

Sun XM, KIm DO. Adaptation of 2f1-2f2 distortion product otoacoustic emission in young-adult and old CBA and C57 mice. J. Acoust. Soc. Am. 105:3399-3409, 1999.

VARGHESE GI, ZhU X, Frisina RD. Age-related declines in contralateral suppression of distortion product otoacoustic emissions utilizing pure tones in CBA/CaJ mice. Hear. Res. 209:60 - 67, 2005.

Vetter DE, Adams JC, Mugnaini E. Chemically distinct rat olivocochlear neurons. Synapse 7:21-43, 1991.

von Hehn CA, Bhattacharjee A, Kaczmarek LK. Loss of Kv3.1 tonotopicity and alterations in cAMP response element-binding protein signaling in central auditory neurons of hearing impaired mice. J. Neurosci. 24:1936-1940, 2004.

Wang L, Gan L, Perney TM, Schwartz I, Kaczmarek LK. Activation of Kv3.1 channels in neuronal spine-like structures may induce local potassium ion depletion. Proc. Natl. Acad. Sci. USA. 95:1882-1887, 1998a.

Wang L, Gan L, Forsythe ID, Kaczmarek LK. Contribution of the Kv3.1 potassium channel to high-frequency firing in mouse auditory neurons. J. Physiol. 509(1):183-194, 1998b.

Weiser M, Vega-Saenz de Miera E, Kentros C, Moreno H, Franzen L, Hillman D, Baker H, Rudy B. Differential expression of Shawrelated $\mathrm{K}^{+}$channels in the rat central nervous system. J. Neurosci. 14:949-972, 1994.

Weiser M, Bueno E, Sekirnjak C, Martone ME, Baker H, Hillman D, Chen S, Thornhill W, Ellisman M, Rudy B. The potassium channel subunit Kv3.1b is localized to somatic and axonal membranes of specific populations of CNS neurons. J. Neurosci. 15:4298-4314, 1995.

WiLliams DM, Brown AM. Contralateral and ipsilateral suppression of the 2f1-f2 distortion product in human subjects. J. Acoust. Soc. Am. 97:1130-1140, 1995.

Willott J. Aging and the Auditory System: Anatomy, Physiology, and Psychophysics. San Diego, Singular Publishing Group, 1991. 